\title{
Serotonin Immunoreactive Boutons Make Synapses with Feline Phrenic Motoneurons
}

\author{
P. M. Pilowsky, ${ }^{1}$ D. de Castro, ${ }^{1}$ I. Llewellyn-Smith, ${ }^{2}$ J. Lipski, ${ }^{1}$ and M. D. Voss ${ }^{1}$ \\ 'Department of Physiology, School of Medicine, University of Auckland, Auckland 1, New Zealand, and 'Department of \\ Medicine, Flinders University, Bedford Park 5042, South Australia
}

In anesthetized cats, phrenic motoneurons were intracellularly labeled with HRP. Immunohistochemistry was used to localize serotonin-like immunoreactivity that was present in numerous boutons and nerve fibers within the ventral horn of the $C_{5}$ spinal segment. Immunoreactive boutons were frequently found in apposition to phrenic motoneurons, but these close contacts were more common on the dendrites than the cell body. At the electron microscope level, serotoninimmunoreactive boutons were found to make synapses with well-defined postsynaptic densities on proximal and distal dendrites of phrenic motoneurons. These results suggest that serotonin-containing neurons may directly affect the $\theta x-$ citability of phrenic motoneurons, mainly through an input onto their extensive dendritic trees.

There is a large body of evidence indicating that serotonincontaining neurons of the brain stem are involved in the central control of respiration. First, a number of pharmacological expcriments have shown that the administration of serotonin precursors or receptor agonists or antagonists elicits changes in the motor activity to respiratory muscle (Millhorn et al., 1980; Eldridge and Millhorn, 1981; Lalley, 1986b; Millhorn, 1986). Second, stimulation of the caudal raphe nuclei in the region of the serotonin-containing cell bodies results in large changes of ventilation (Holtman et al., 1986a; Lalley, 1986a, b; Millhorn, 1986) and an activation of phrenic motoneurons that can be partially blocked with serotonin receptor antagonists (Holtman et al., 1986b; Lalley, 1986b; Holtman et al., 1987). Third, the longterm potentiation of the firing of respiratory motoneurons that follows stimulation of carotid body chemoreceptors or chemoreceptor afferents can be prevented by pretreatment with serotonin receptor antagonists (Millhorn et al., 1980).

It has been suggested (Holtman et al., 1986b; Lalley, 1986b) that activation of serotonergic neurons affects the activity of respiratory motoneurons indirectly, by changing the firing rate of premotor respiratory neurons in the brain stem. A monosynaptic action of serotonergic neurons onto respiratory mo-

\footnotetext{
Received April 3, 1989; revised Sept. 12, 1989; accepted Sept. 25, 1989.

This study was supported by the Auckland Medical Research Foundation, New Zealand Medical Research Council, and the Wellcome Trust (U.K.). The authors are grateful for the technical assistance of Ms. V. Yardley and Mr. A. Wright and the secretarial assistance of Ms. M. Loo. P.M.P. is an Overseas Research Fellow of the National Heart Foundation and National Health and Medical Research Council of Australia. We are grateful to Dr. W. Watkins for his generous gift of the polyclonal serotonin antiserum.

Correspondence should be addressed to Prof. J. Lipski, Department of Physiology, School of Medicine, University of Auckland, Private Bag, Auckland 1, New Zealand.

Copyright (C) 1990 Society for Neuroscience $0270-6474 / 90 / 041091-08 \$ 02.00 / 0$
}

toneurons was considered unlikely for several reasons. First, the responses evoked by electrical stimulation of the raphe nuclei were too rapid in onset to be accounted for by slowly conducting bulbospinal serotonergic fibers (Wessendorf et al., 1981; Yen and Blum, 1984; Holtman et al., 1986b; Lalley, 1986b). Second, microelectrophoresis of serotonin onto phrenic motoneurons had no significant effect on their firing rate (Lalley, 1986b). Third, the ventilatory responses evoked by stimulation of the raphe nuclei were accompanied by changes in respiratory frequency, indicating an involvement of the brain-stem generator of the respiratory rhythm (Millhorn, 1986).

These physiological studies do not support a direct role for bulbospinal serotonin-containing neurons in the control of the excitability of respiratory motoneurons. On the other hand, some anatomical studies have provided evidence that does support such a role. Holtman et al. (1984a) have demonstrated a projection from the raphe nuclei, mainly obscurus and pallidus, to the $\mathrm{C}_{5}$ and $\mathrm{C}_{6}$ segments of the spinal cord in the region of the phrenic nucleus. More recently, Bowker ct al. (1987) have shown that most raphe-spinal neurons are serotonergic. In addition, serotonin-like immunoreactivity has been demonstrated in axons and terminal boutons among the cell bodies of retrogradely labeled phrenic motoneurons (Holtman et al., 1984b; Zhan et al., 1989). In these studies (Holtman et al., 1984b; Zhan et al., 1989), only the cell bodies and proximal dendrites of phrenic motoneurons were labeled, and dendritic appositions could not be fully examined.

Since a number of studies of other neurons in the central nervous system have reported that serotonin-immunoreactive boutons were found mainly on dendrites (Maley and Elde, 1982; Miletic et al., 1984; Hylden et al., 1986; Ulfhake et al., 1987), it was considered important to examine the location of serotonin-immunoreactive boutons on phrenic motoneurons in more detail. In the present study, we have examined the location of serotonin-containing boutons on both the soma and dendrites of individual phrenic motoneurons by using a combination of intracellular recording and labeling, and immunohistochemistry. This was achieved in two stages. First, we determined the location of boutons that appeared to be in close contact with labeled phrenic motoneurons. Second, we demonstrated that at least some of these labeled boutons form morphologically identifiable synapscs using electron microscopic techniques. A preliminary account of this work has been presented to the Society for Neuroscience (Lipski et al., 1988).

\section{Materials and Methods}

Electrophysiology and tissue preparation. The experiments were performed on 3 adult cats, anesthetized with sodium pentobarbital (Nem- 


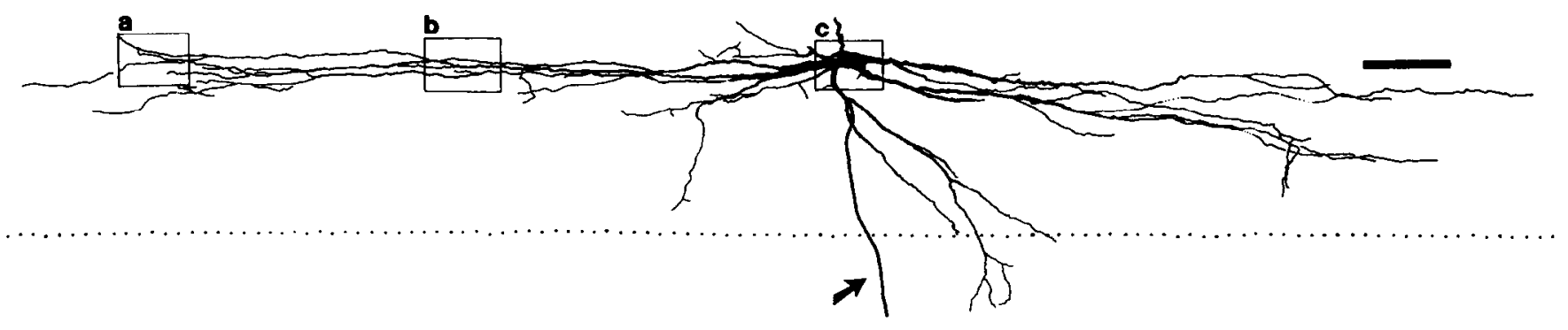

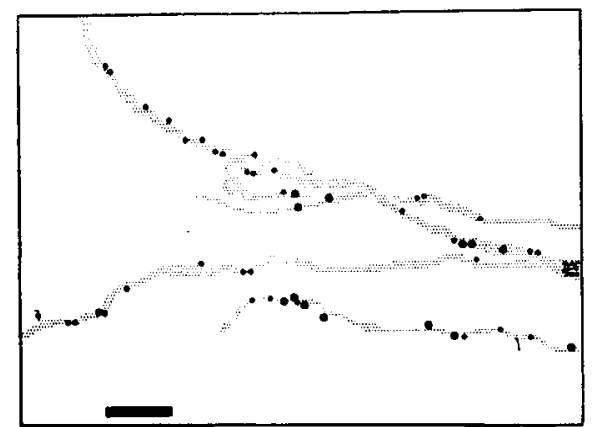

a

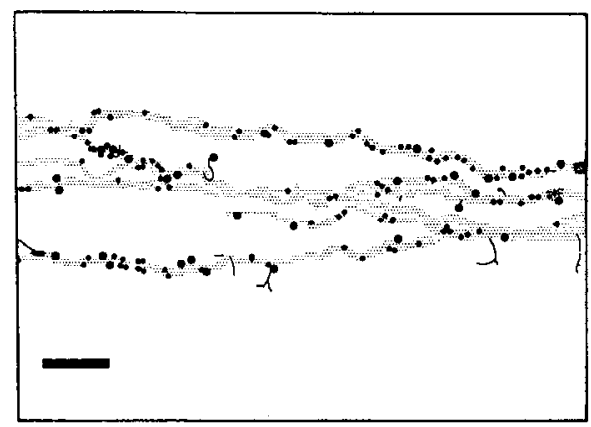

b

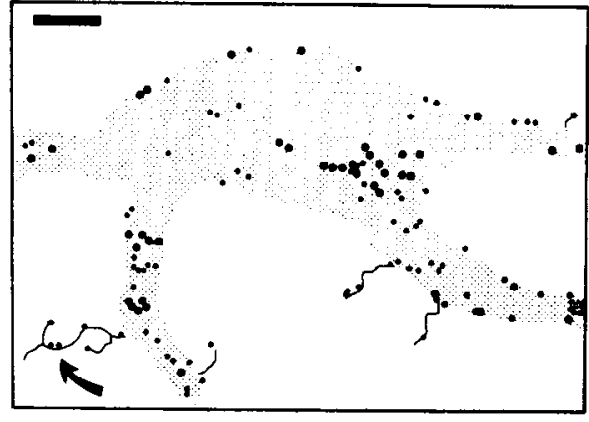

C

Figure 1. Camera lucida reconstruction of a phrenic motoneuron. The areas indicated by the small boxes $(a, b, c)$ were reconstructed using a $100 \times$ oil immersion lens and are shown at larger scale below. Sites at which serotonin immunoreactive boutons were found in close contact are indicated with filled circles. Small circles indicate boutons $<1 \mu \mathrm{m}$ in diameter; large circles those $>1 \mu \mathrm{m}$. The axon is indicated by the arrow in the upper panel. The dotted line shows the border between the gray and white matter. The arrow in $c$ indicates a number of boutons in close contact with an appendage. Scale bar for upper panel, $200 \mu \mathrm{m}$; for lower panels, $20 \mu \mathrm{m}$.

butal, $40 \mathrm{mg} / \mathrm{kg}$, IP). A laminectomy was performed at the $\mathrm{C}_{4}$ to $\mathrm{C}_{6}$ level, and both the left and right $\mathrm{C}_{5}$ phrenic roots were prepared for standard bipolar stimulation and/or recording. Intracellular recordings were obtained using glass microelectrodes (resistance, 20-40 M 2 , tip diametcr, $0.5-1.0 \mu \mathrm{m}$ ) filled with a $10 \%$ solution of HRP (Scrva) in 0.1 м Tris- $\mathrm{HCl}$ buffer (pH 7.6) containing $0.3 \mathrm{M} \mathrm{KCl}$. Neurons that could be antidromically activated following stimulation of the $\mathrm{C}_{5}$ phrenic root, and that showed a depolarizing shift of membrane potential during phrenic nerve discharge, were considered to be phrenic motoneurons, and injected with HRP. HRP was injected iontophoretically using 5$15 \mathrm{nA}$ positive current pulses ( $400 \mathrm{msec}$ on, $100 \mathrm{msec}$ off). At least 1 hr after the last motoneuron was injected, the animals were perfused transcardially with $0.9 \% \mathrm{NaCl}$ and then with $4 \%$ formaldehyde and $0.2 \%$ glutaraldehyde in $0.1 \mathrm{M}$ phosphate buffer ( $\mathrm{pH} 7.4$ ) for light microscopy (LM), or with $1 \%$ formaldehyde and $1 \%$ glutaraldehyde in phosphate buffer for electron microscopy (EM). Sagittal sections (50 $\mu \mathrm{m}$ ) of the $\mathrm{C}_{5}$ cervical segment were cut using a Vibratome.

Staining procedures. For LM studies, the location of HRP-filled neurons was revealed by either the Hanker-Yates reaction (Hanker ct al., $1977)$ or the nickel-intensified diaminobenzidine (DAB) reaction $(0.02 \%$ DAB, $0.6 \%$ nickel ammonium sulfate, $0.003 \%$ hydrogen peroxide). In both cases the reaction was terminated after $15 \mathrm{~min}$. The sections were then washed 3 times for $10 \mathrm{~min}$ in a modified Tris-phosphate buffer (Pilowsky et al., 1986) and incubated in a rabbit antibody to serotonin (Dr. W. Watkins, Auckland) diluted 1:2000 in the same buffer containing $20 \%$ porcine serum for $48 \mathrm{hr}$ at room temperature. After 3 more 10 -min washes, the sections were incubated overnight in a biotinylated sheep anti-rabbit antibody (Sigma, B9140) in 1\% porcine serum. After 3 more $10-\mathrm{min}$ washes and a $1-\mathrm{hr}$ incubation in an avidin-peroxidase conjugate $(1: 1000$. Sigma A3151), the sections were again washed 3 times for $10 \mathrm{~min}$. The location of serotonin-immunoreactive nerve terminals was then revealed by incubating the sections in a solution containing $0.05 \% \mathrm{DAB}, 10 \mathrm{~mm}$ imidazole-4-acetate, and $0.03 \%$ hydrogen peroxide. After further washes, the sections were mounted onto subbed slides, dehydrated, cleared in xylene, and mounted with Depex.

For EM studies, HRP-filled neurons were visualized by an imidazoleintensified $\mathrm{DAB}$ reaction. To enhance antibody penetration, the sections were washed with $50 \%$ ethanol in distilled water for $30 \mathrm{~min}$, and then with $0.1 \%$ sodium cyanoborohydride (Aldrich) in phosphate buffer for 30 min (modified from Llewellyn-Smith et al., 1985). The sections were then incubated for $30 \mathrm{~min}$ in 10\% normal sheep serum (NSS) diluted with phosphate-buffered saline ( $\mathrm{pH} 7.4)$ containing $10 \mathrm{~mm}$ Tris and $0.05 \%$ merthiolate (TPBS), for $3 \mathrm{~d}$ in 1:4000 rat monoclonal antiserotonin antibody (Seralab) in 10\% NSS-TPBS, for $24 \mathrm{hr}$ in a 1:200 biotinylated goat anti-rat immunoglobulin (Sigma, B7139) in 1\% NSSTPBS, and overnight in 1:1500 ExtrAvidin-peroxidase (Sigma E2886) in TPBS. Sections were washed 3 times for $30 \mathrm{~min}$ in TPBS after each incubation. Serotonin-immunoreactive nerve fibers were revealed by a peroxidase reaction. The reaction mixture contained $0.5 \mathrm{mg} / \mathrm{ml} \mathrm{DAB}$, $50 \mathrm{~mm}$ Tris- $\mathrm{HCl}$ (pH 7.6), $10 \mathrm{~mm}$ imidazole, $0.004 \% \mathrm{NH}_{4} \mathrm{Cl}$, and $0.2 \%$ D-glucose (Straus, 1982; Oldfield et al., 1983). Sections were soaked in this reaction mix for $10 \mathrm{~min} ; 1 \mu$ of glucose oxidase (Sigma, G6891) per $\mathrm{ml}$ of reaction mixture was added and the reaction was allowed to proceed for $30 \mathrm{~min}$. Sections containing HRP-filled neurons and immunoreactive nerve fibers were then exposed to $0.5 \%$ osmium tetroxide in $0.1 \mathrm{M}$ phosphate buffer for $1 \mathrm{hr}$, stained en bloc with $2 \%$ aqueous uranyl acetate, dehydrated with alcohol and propylene oxide, and embedded flat on slides in Durcupan AM resin (Fluka). Areas containing HRP-filled dendrites with apposed serotonin nerve fibers were identified by $\mathrm{LM}$ and then reembedded for EM sectioning. Serial silver to pale gold ultrathin sections were mounted on butvar-coated single slot grids, stained with Reynold's lead citrate, and examined with a JEOL 1200EX electron microscope.

Light microscopic analysis. The sections were examined with a $10 \times$ or $25 \times$ objective in order to locate HRP-filled cell bodies and dendrites. A $100 \times$ oil immersion objective was used to assess the proximity of serotonin-immunoreactive boutons to labeled phrenic motoneurons. Reconstructions of HRP-filled neurons and immunoreactive profiles were performed using a camera lucida technique. Low-power reconstructions were used to assess the extent of dendritic arborization, and high-power reconstructions were used to assess whether or not boutons were in close contact with phrenic motoneurons. Boutons and labeled neurons were considered to be in close contact if they were found side by side with no discernible gap between them. 

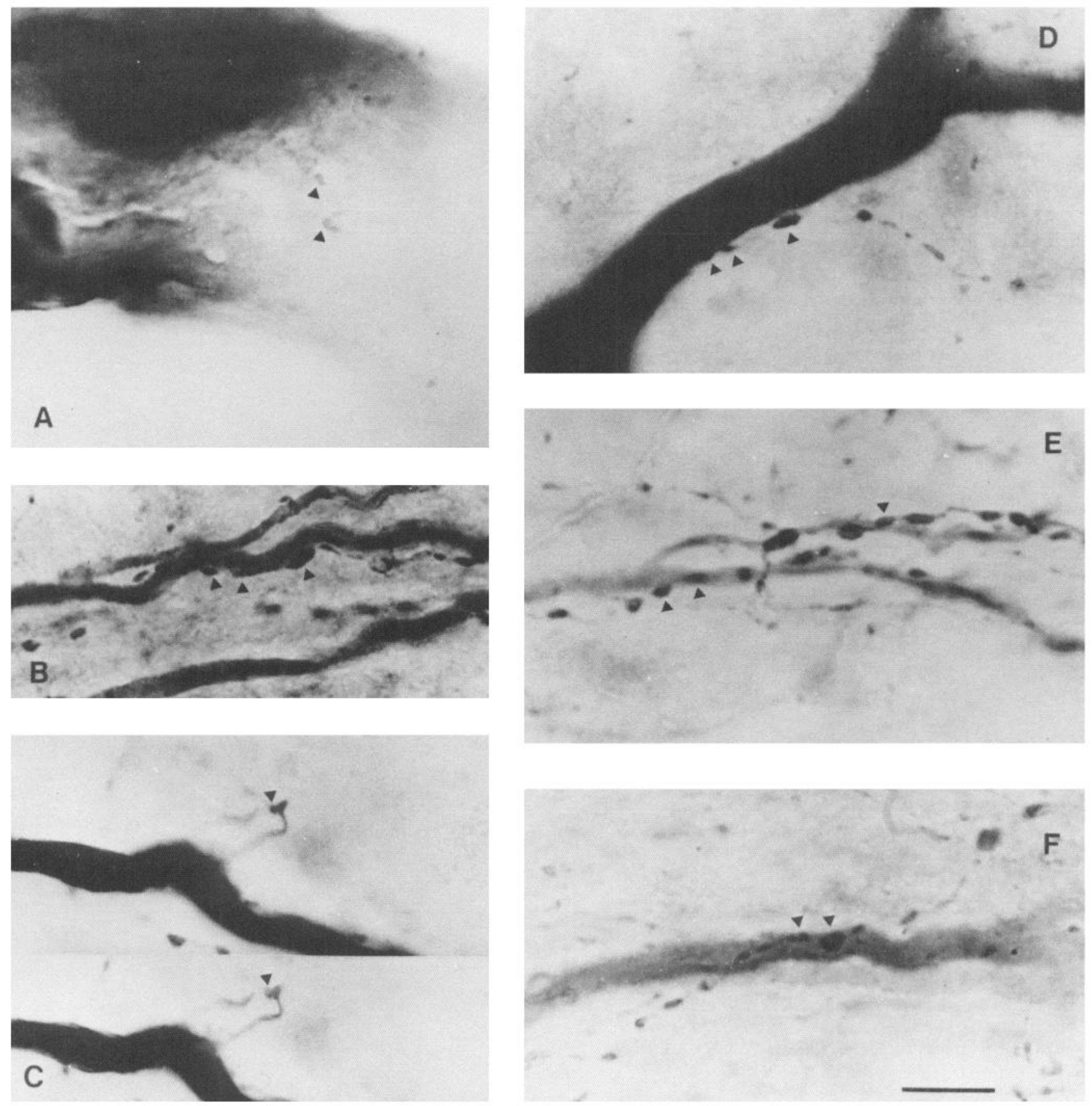

Figure 2. Light micrographs showing serotonin-immunoreactive boutons and HRP-filled phrenic motoneurons. $A$, Soma of a phrenic motoneuron. $B$, Close contacts on a proximal dendrite. $C$, A bouton in close contact with a dendritic appendage. This micrograph shows the same site at 2 focal planes. $D$, A dendrite adjacent to the soma. $E$, A distal dendrite with several boutons forming close contacts. $F$, A proximal dendrite with a bouton overlying the dendrite. In each case indicated by the arrowheads in $B, C$, and $D$, no discernible gap was seen at at least one focal plane, whereas at other focal planes a gap was sometimes seen. This effect is illustrated in $C$, which is a photograph of the same structure at 2 focal planes. In $A$, $E$, and $F$, a distance of less than $2 \mu \mathrm{m}$, as determined from the microscope stage, between the point of best focus of the bouton and the point of best focus of the labeled neuronal profile was found at the sites indicated by arrowheads. Scale bar, $10 \mu \mathrm{m}$. The magnification is the same for all micrographs.

\section{Results}

\section{Phrenic motoneurons}

In 2 cats, a total of 11 electrophysiologically identified phrenic motoneurons that were intracellularly labeled with HRP were recovered after reaction with the Hanker-Yates. Of these 11 neurons, 8 were sufficiently well stained to enable a detailed analysis at the LM level. In these 8 neurons it was possible to reconstruct dendrites that traveled rostrocaudally for distances of at least $500 \mu \mathrm{m}$, and in 5 of them for distances of more than $1500 \mu \mathrm{m}$, from the soma. 


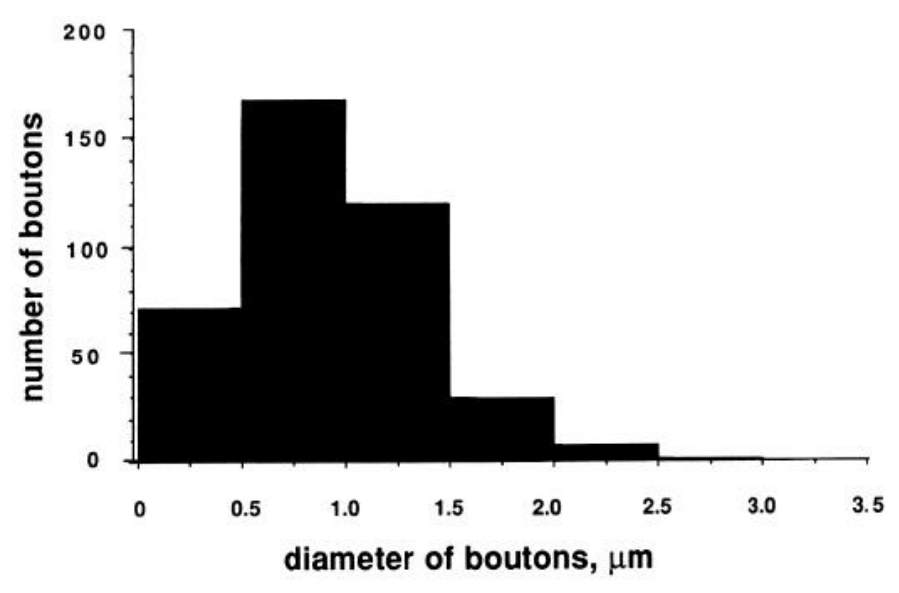

Figure 3. Size distribution of boutons in close contact with a phrenic motoneuron.

An example of a phrenic motoneuron reconstructed in the sagittal plane is shown in Figure 1. This figure also illustrates the pronounced dendritic projection in the rostrocaudal direction from the cell body as well as the 4 areas of the dendritic field that were used for detailed examination. The phrenic motoneurons in this study showed a rostrocaudal spread of dendrites similar to that described in previous studies (Cameron et al., 1983; Lipski et al., 1985). As with both of these previous studies, dendritic spines and appendages were common. No axon collaterals were noted in 8 examined axons. This is consistent with previous work showing the presence of axon collaterals in only 6 of 49 labeled phrenic motoneurons (Lipski et al., 1985). In a third cat, 4 motoneurons were filled with HRP and reacted with DAB for subsequent EM analysis.

\section{Serotonin immunoreactivity}

At the LM level, a dense network of serotonin immunoreactive fibers was found in the ventral horn of the $C_{5}$ segment, which includes the region of the phrenic nucleus. No cell bodies were found that contained serotonin immunoreactivity. All parts of the labeled phrenic motoneurons that we examined were found to have close contacts with serotonin-immunoreactive boutons. Some examples are shown in Figure 2. Close contacts appeared to be least frequent on the soma, most frequent on the distal dendrites, and with intermediate densities on proximal dendrites. Where spines or appendages were found, it was common to find a bouton in close contact (Fig. 2C).

The size of boutons in close contact with 1 neuron was measured. Bouton size was estimated from camera lucida drawings. A histogram of the size distribution of boutons that were observed to be in close contact with a phrenic motoneuron is shown in Figure 3. Bouton diameter was variable $(0.5-3.0 \mu \mathrm{m})$, but no evidence was found for a polymodal distribution of bouton size (Fig. 3).

Tissue fixed for EM with $1 \%$ glutaraldehyde and $1 \%$ formaldehyde appeared to show fewer serotonin-positive nerve fibers than tissue fixed for LM with lower concentrations of glutaraldehyde. However, the alcohol washing and cyanoborohydride treatment allowed immunoreactive varicosities to be stained throughout the thickness of the Vibratome sections containing phrenic motor neurons. Thus, it was easy to find serotonin varicosities next to HRP-filled dendrites for reembedding and ultrastructural analysis.

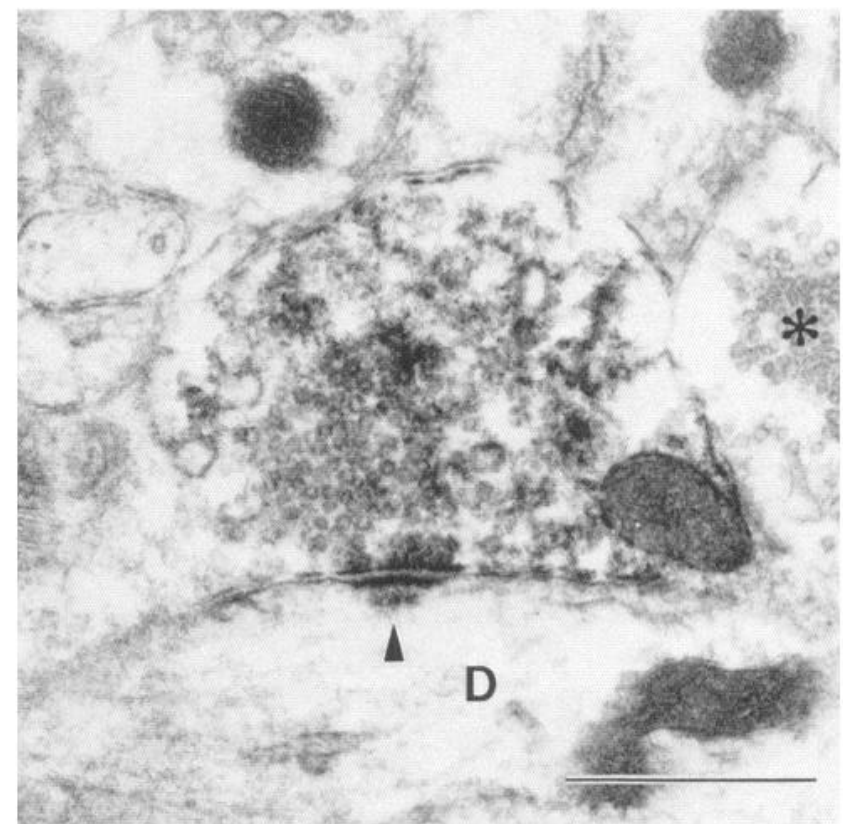

Figure 4. Electron micrograph of a serotonin synapse on an unlabeled dendrite $(D)$ in the phrenic motor nucleus. The synaptic site shows a postsynaptic density and subsynaptic specialization (arrowhead). The asterisk indicates a nonimmunoreactive bouton. Scale bar, $500 \mathrm{~nm}$.

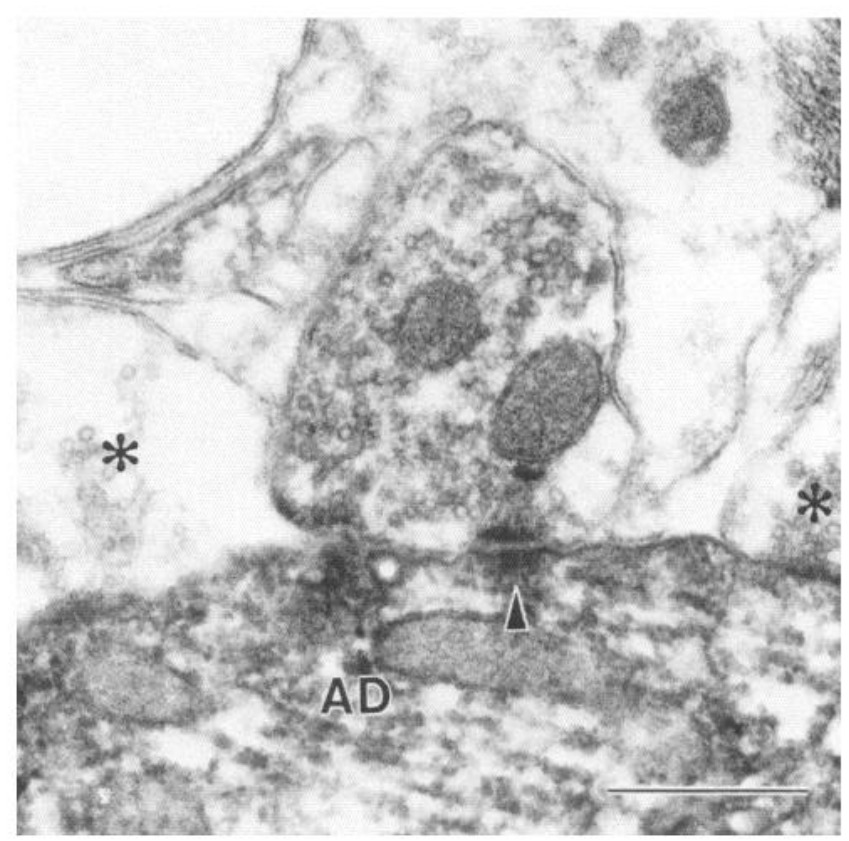

Figure 5. Electron micrograph of a serotonin synapse on an adjacent dendrite $(A D)$ of an electrophysiologically identified phrenic motoneuron. The synapse (arrowhead) was located less than $25 \mu \mathrm{m}$ from the neuronal cell body. Electron-dense peroxidase reaction product is present in the dendrite (due to filling of the phrenic motor neuron with HRP) and in the bouton that forms the synapse (due to the immunocytochemical detection of serotonin). In the 5-HT-positive bouton, vesicles are clustered presynaptically and a membrane specialization is evident postsynaptically (arrowhead). The asterisks indicate nonimmunoreactive boutons. Scale bar, $500 \mathrm{~nm}$. 
At the EM level, serotonin-immunoreactive synapses were found on unlabeled dendrites (Fig. 4) and on the HRP-filled dendrites of identified phrenic motoneurons (Figs. 5, 6). The profiles that formed synapses contained predominantly small round vesicles; only occasionally were large granular vesicles encountered. Four serotonin-positive varicositics apposed to HRP-labeled dendrites were followed in serial sections. One varicosity was on an adjacent dendrite less than $25 \mu \mathrm{m}$ from the cell body (Fig. 5). The other 3 varicosities were apposed to dendrites more than $500 \mu \mathrm{m}$ from the cell body (2 are shown in Fig. 6). All 4 of the varicosities abutting the HRP-filled dendrites formed synapses with well-defined postsynaptic densities. One the synapses on a distal dendrite was doughnut-shaped (Fig. $6 A$ ). In addition to the serotonin-immunoreactive synapses, the HRP-labeled dendrites received many nonimmunoreactive synapses.

\section{Discussion}

\section{Methodological considerations}

An advantage of the technique of combined intracellular labeling and immunohistochemistry is that it is possible to examine the full extent of the dendritic tree and thus determine where on the cell the major input is likely to be arriving. The technique is also advantageous for EM immunocytochemical studies since immunoreactive synapses can easily be identified on dendrites that are very distant from the cell body. These distal dendrites may receive a large number of inputs from immunoreactive fibers, as they did in this study. In contrast, when neurons are labeled by retrograde transport, usually only the inputs to their cell bodies and proximal dendrites can be examined because retrograde label does not reach distant dendrites.

A possible limitation with studies of this kind is confusion between the immunoreactive profiles and the filled neuron. First, intrinsic neurons containing serotonin may be confused with HRP-filled neurons. Second, recurrent collaterals of intracellularly labeled neurons may be confused with immunoreactive fibers. Third, at the LM level, densely labeled HRP-filled neurons may obscure immunoreactive boutons. In this study the first 2 problems were not encountered since no serotonin-immunoreactive somata were observed within the $\mathrm{C}_{5}$ segment of the spinal cord, and no collateral branches were observed in axons of the labeled motoneurons. In a previous study in which axon collaterals were observed in a small proportion of phrenic motoncurons, these could only be traced for relatively short distances, and rarely beyond their first branch point (Lipski et al., 1985). Finally, it is possible that in our LM study some immunoreactive varicosities could be obscured by HRP reaction product, particularly on the soma. We feel that with careful examination using a $100 \times$ oil immersion objective, the degree of underestimation is likely to be small if the bouton size is more than $1 \mu \mathrm{m}$. Greater difficulties are encountered with smaller boutons, with an increased likelihood of false positive or negative counts.

\section{Bouton distribution and synapses}

The present, as well as previous, studies (Cameron et al., 1983; Lipski et al., 1985) demonstrated an extensive dendritic field of phrenic motoneurons, particularly the large rostrocaudal projection. Our observation that the serotonergic input is directed mainly toward the dendrites of phrenic motoneurons is in accord with the findings of Takahashi and Ninomiya (1985), who showed that phrenic motoneurons in the cat have abundant axodendritic, but few axosomatic, synapses.

This finding is also in accord with other studies of the distribution of serotonin-immunoreactive boutons on other spinal or brain-stem neurons (Maley and Elde, 1982; Miletic et al., 1984; Hylden et al., 1986). In the reports by Hylden et al. (1986) and Miletic et al. (1984) concerning dorsal horn neurons, boutons were found only exceptionally on cell bodies. On the other hand, these authors reported that despite numerous dendritic spines, contacts were almost invariably found only on dendritic shafts. Phrenic motoneurons have fewer spines, but serotoninimmunoreactive boutons commonly formed contacts with them.

Our examination of serial sections of 4 serotonin-immunoreactive boutons apposed to HRP-filled dendrites showed that all 4 formed synapses with well-defined postsynaptic specializations. Serotonin-immunoreactive synapses were also found on unfilled dendrites in the $C_{5}$ ventral horn. Maley and Elde (1982) reported that in the nucleus of the solitary tract of cat some serotonin boutons did not form synapses. We also found nonsynaptic serotonin varicosities, but none of these was followed in serial sections. Thus, our EM findings suggest that serotonin synapses are common in the phrenic motor nucleus, but it is also possible that some serotonin varicosities do not make morphologically identifiable synaptic contacts.

\section{Bouton size}

The size distribution of serotonin-immunoreactive boutons in contact with phrenic motoneurons shows a single population ranging from lcss than $1 \mu \mathrm{m}$ to $3 \mu \mathrm{m}$. There was no clear bimodal distribution of boutons that were less than or greater than $1 \mu \mathrm{m}$, as has been reported in the cat cerebral cortex by Mulligan and Tork (1988). Since these authors have reported that the overall number of larger boutons is small compared to boutons with a diameter of less than $1 \mu \mathrm{m}$, it is possible that phrenic motoneurons are preferentially innervated by boutons of the larger size.

\section{Functional implications}

The finding that phrenic motoneurons receive a direct synaptic input from serotonin-immunoreactive boutons strongly suggests a monosynaptic interaction between bulbospinal serotonin neurons with cell bodies in the raphe nucleus and these motoneurons. The analysis of the location of the immunoreactive boutons indicates that the dendritic input plays a major role in the control of the excitability of thesc motoncurons. The nature of this interaction and its importance in the control of ventilation are still unclear. Previous studies involving iontophoresis of serotonin onto phrenic motoneurons have failed to demonstrate an effect (Lalley, 1986b). This result may be partly explained by the relative paucity of serotonin-containing boutons on the somata of phrenic motoneurons possibly associated with a smaller number of serotonin receptors in that region. Alternatively, serotonin may only exert a significant "gain setting" effect in the presence of other neurotransmitters, as has been suggested by others (McCall and Aghajanian, 1979; White and Neuman, 1980), or serotonin may be involved in the calcium-dependent bistability of the postsynaptic membrane (Hounsgaard and Kiehn, 1985). Serotonin has also been demonstrated to reduce the afterhyperpolarization in other motoneurons (Van Dongen et al., 1986).

$\Lambda$ further possibility is that a colocalized transmitter mediates neurotransmission at these synapses. Neurotransmitters or their 

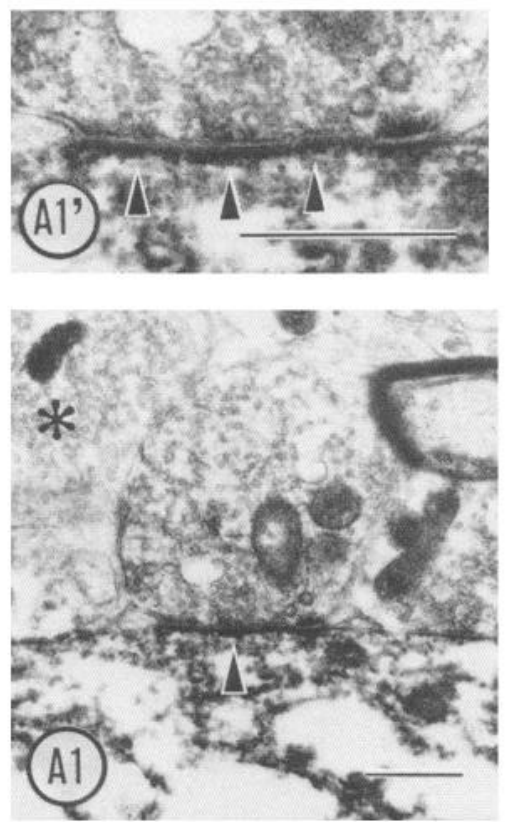
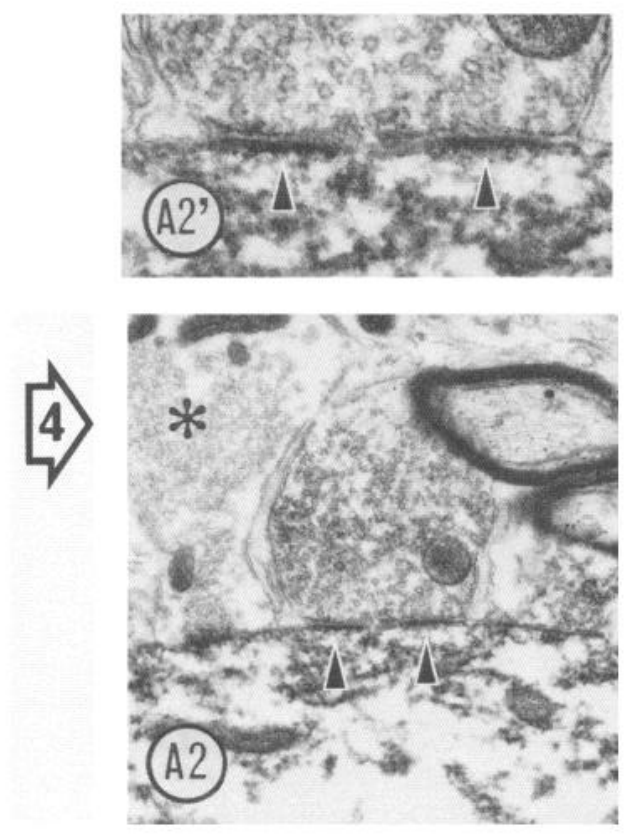

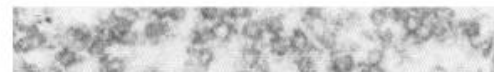

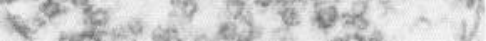

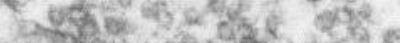

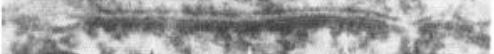
(A3, 12,120

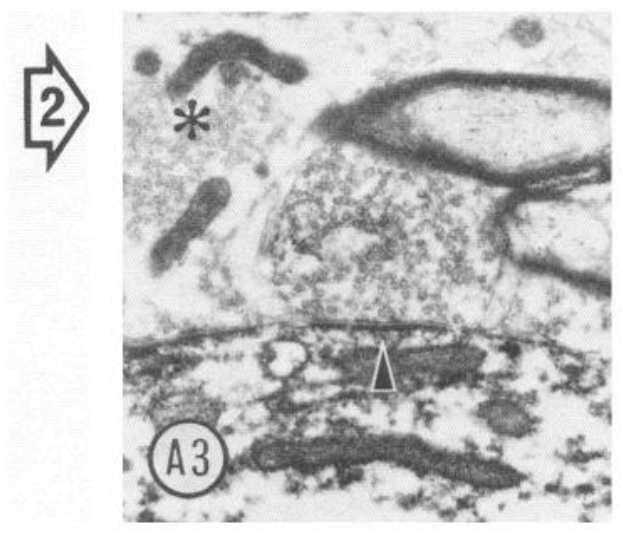

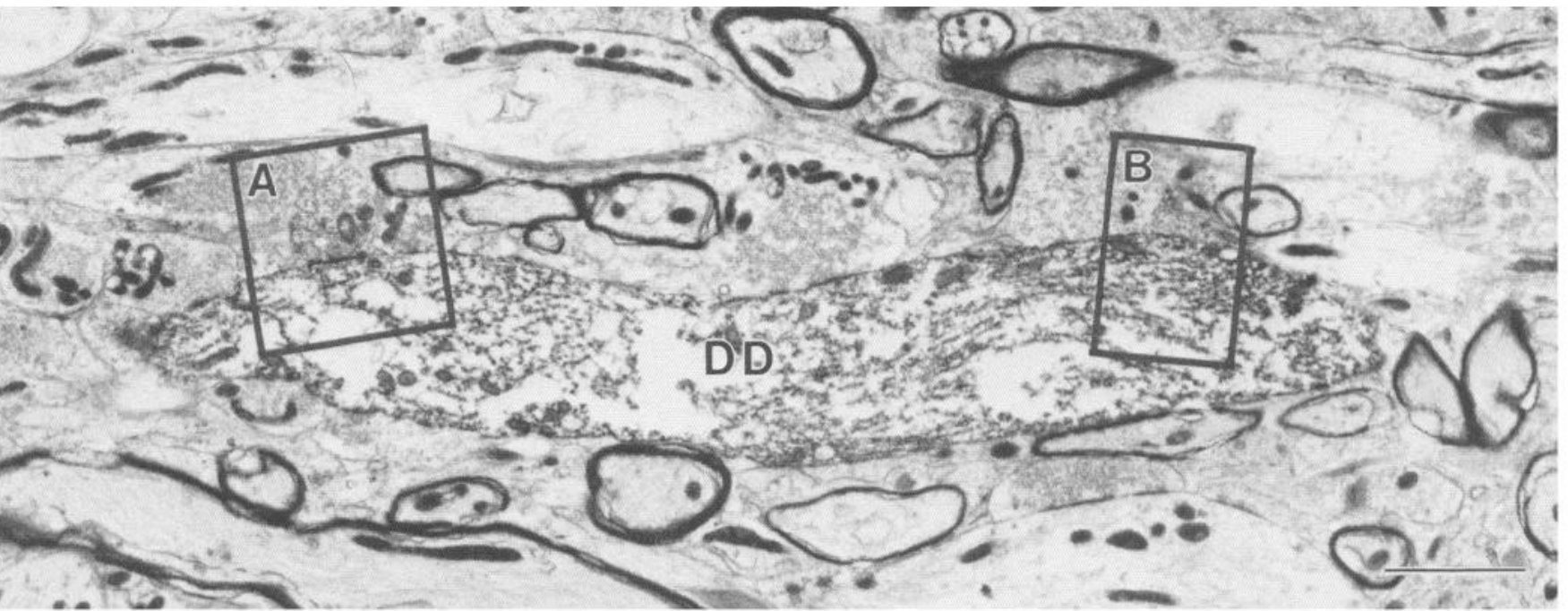
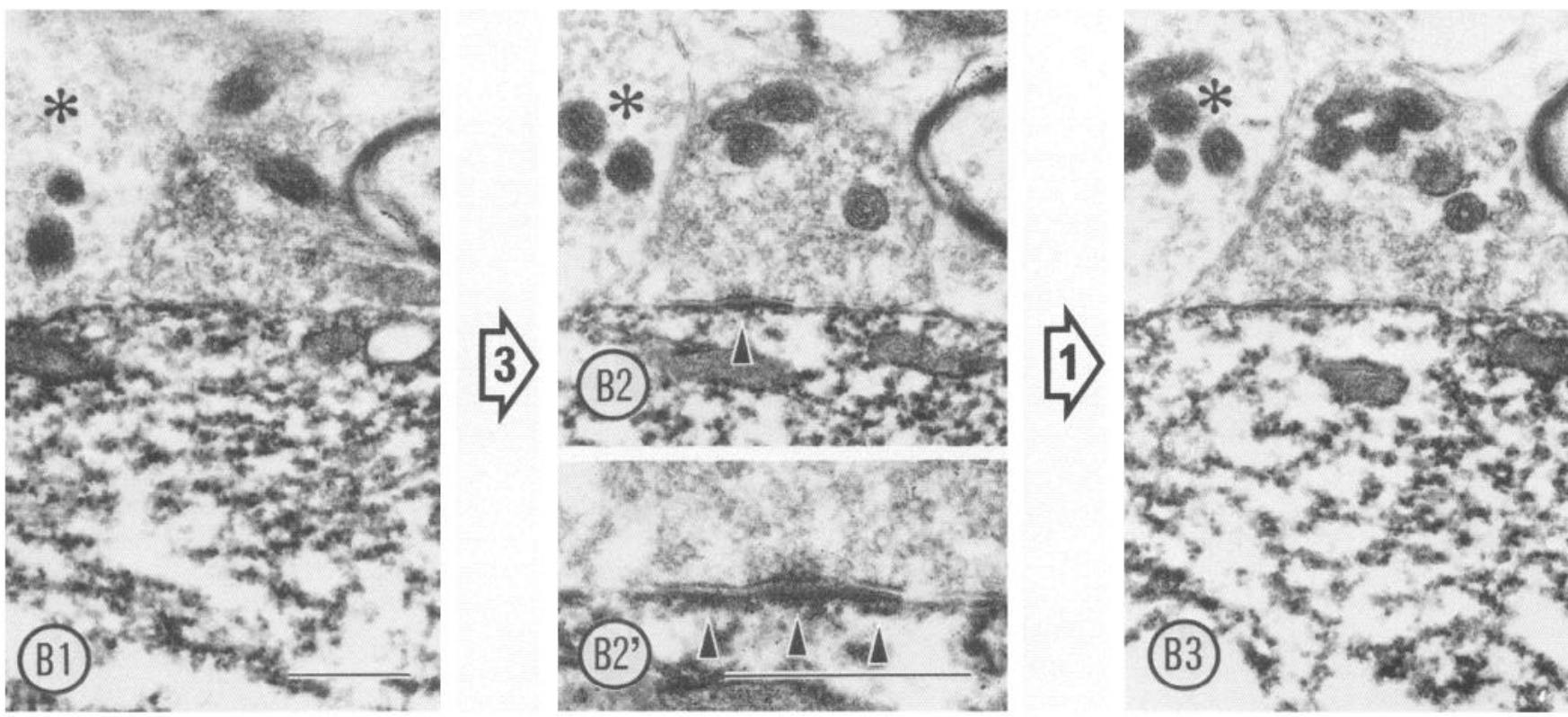

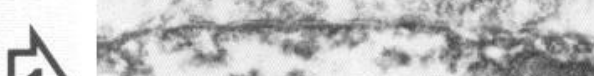

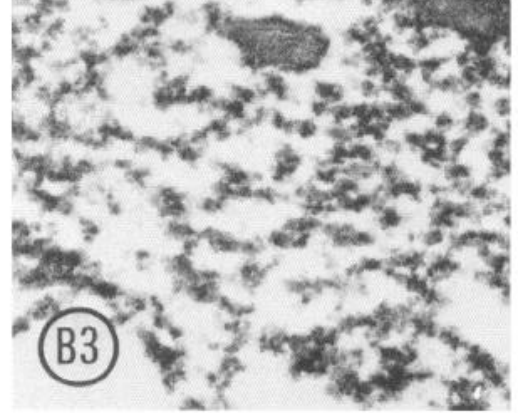


synthesizing enzymes that have been colocalized within bulbospinal serotonin-immunoreactive profiles include peptides such as substance $P$, thyrotropin-releasing hormone, and metenkephalin (Bowker et al., 1981; Johansson et al., 1981; Pelletier et al., 1981; Leger et al., 1986; Wessendorf and Elde, 1988; Tashiro and Ruda, 1988) and the inhibitory amino acid GABA (Millhorn et al., 1987).

Finally, the present results do not exclude a possible role for serotonin acting through medullary respiratory neurons, including the ventral and dorsal groups of bulbospinal neurons. A histological examination of these neurons and their relationship to serotonin-containing nerve terminals has revealed a relatively weak serotonergic input to neurons in the dorsal respiratory group in the medulla of the cat (Voss et al., 1990). An examination of the serotonergic input to neurons in the ventral respiratory group has not so far been reported. Clearly, further studies are needed to elucidate the role of serotonin in respiratory control. Perhaps this input sets a basal level of excitability of both spinal and brain-stem respiratory neurons that is modulated by other transmitter systems, rather than influencing directly the rhythm and pattern of respiratory movements. This role seems to be supported by the finding that, at least in the dorsal raphe nucleus, serotonin neurons fire in a highly regular fashion that is unaltered in situations that elicit large changes in the pattern of ventilation (Fornal et al., 1987).

\section{References}

Bowker, R. M., H. W. M. Steinbusch, and J. D. Coulter (1981) Serotonergic and peptidergic projections to the spinal cord demonstrated by a combined retrograde HRP histochemical and immunocytochemical staining method. Brain Res. 211: 412-417.

Bowker, R. M., V. K. Reddy, S. J. Fung, J. Y. H. Chan, and C. D. Barnes (1987) Serotonergic and non-serotonergic raphe neurons projecting to the feline lumbar and cervical spinal cord: A quantitative horseradish peroxidase-immunocytochemical study. Neurosci. Lell. 75: $31-37$

Cameron, W. E., D. B. Averill, and A. J. Berger (1983) Morphology of cat phrenic motoneurons as revealed by intracellular injection of horseradish peroxidase. J. Comp. Neurol. 219: 70-80.

Eldridge, F. L., and D. E. Millhorn (1981) Central regulation of respiration by endogenous neurotransmitters and neuromodulators. Annu. Rev. Physiol. 43: 121-135.

Fornal, C., W. J. Litto, D. A. Morilak, and B. I. Jacobs (1987) Single unit responses of serotonergic dorsal raphe nucleus neurons to environmental heating and pyrogen administration in freely moving cats. Exp. Neurol. 98: 388-403.

Hanker, J. S., P. E. Yates, C. B. Metz, and A. Rustioni (1977) A new specific, sensitive and non-carcinogenic reagent for the demonstration of horseradish peroxidase. Histochem. J. 9: 789-792.

Holtman, J. R., W. P. Norman, and R. A. Gillis (1984a) Projections from the raphe nuclei to the phrenic motor nucleus in the cat. Neurosci. Lett. 44: 105-111.

Holtman, J. R., W. P. Norman, L. Skirboll, K. L. Dretchen, C. Cuello, T. J. Visser, T. Hökfelt, and R. A. Gillis (1984b) Evidence for 5-hydroxytryptamine, substance $\mathrm{P}$, and thyrotropin-releasing hor- mone in neurons innervating the phrenic motor nucleus. J. Neurosci. 4: 1064-1071.

Holtman, J. R., N. C. Anastasi, W. P. Norman, and K. L. Dretchen (1986a) Effect of electrical and chemical stimulation of the raphe obscurus on phrenic nerve activity in the cat. Brain Res. 362: 214220.

Holtman, J. R., T. E. Dick, and A. J. Berger (1986b) Involvement of serotonin in the excitation of phrenic motoneurons evoked by stimulation of the raphe obscurus. J. Neurosci. 6: 1185-1193.

Holtman, J. R., T. R. Dick, and A. J. Berger (1987) Serotonin-mediated excitation of recurrent laryngeal and phrenic motoneurons evoked by stimulation of the raphe obscurus. Brain Res. 417: 12-20.

Hounsgaard, J., and O. Kiehn (1985) $\mathrm{Ca}^{+}$dependent bistability induced by serotonin in spinal motoneurons. Exp. Brain Res. 57: 422425.

Hylden, J. L. K., H. Hayashi, M. A. Ruda, and R. Dubner (1986) Serotonin innervation of physiologically identified lamina 1 projection neurons. Brain Res. 370: 401-404.

Johansson, O., T. Hökfelt, B. Pernow, S. L. Jeffcoate, N. White, H. W. M. Steinbusch, A. A. J. Verhofstad, P. C. Emson, and E. Spindel (1981) Immunohistochemical support for three putative transmitters in one neuron: Co-existence of 5-hydroxytryptamine-, substance Pand thyrotropin releasing hormone-like immunoreactivity in medullary ncurons projecting to the spinal cord. Ncuroscience 6: 18571881 .

Lalley, P. M. (1986a) Responses of phrenic motoneurones of the cat to stimulation of medullary raphe nuclei. J. Physiol. 380: 349-371.

Lalley, P. M. (1986b) Serotonergic and non-serotonergic responses of phrenic motoneurones to raphe stimulation in the cat. J. Physiol. 380 : 373-385.

Leger, L., Y. Charnay, P. M. Dubois, and M. Jouvet (1986) Distribution of enkephalin-immunoreactive cell bodies in relation to serotonin-containing neurons in the raphe nuclei of the cat: Immunohistochemical evidence for the co-existence of enkephalins and serotonin in certain cells. Brain Res. 362: 63-73.

Lipski, J., R. E. W. Fyffe, and J. Jodkowski (1985) Recurrent inhibition of cat phrenic motoneurons. J. Neurosci. 5: 1545-1555.

Lipski, J., P. M. Pilowsky, M. D. Voss, and D. de Castro (1988) Scrotonin immunoreactive boutons make close contacts with feline phrenic motoneurons. Soc. Neurosci. Abstr. 14: 379.6.

Llewellyn-Smith, I. J., M. Costa, and J. B. Furness (1985) Light and electron microscopic immunocytochemistry of the same nerves from whole mount preparations. J. Histochem. Cytochem. 33: 857-866.

Maley, B., and R. Elde (1982) The ultrastructural localization of serotonin immunoreactivity within the nucleus of the solitary tract of the cat. J. Neurosci. 2: 1499-1506.

McCall, R. B., and G. K. Aghajanian (1979) Serotonergic facilitation of facial motoneurone excitation. Brain Res. 169: 11-27.

Miletic, V., M. J. Hoffert, M. A. Ruda, R. Dubner, and Y. Shigenaga (1984) Serotonergic axonal contacts on identified cat spinal dorsal horn neurons and their correlation with nucleus raphe magnus stimulation. J. Comp. Neurol. 228: 129-141.

Millhorn, D. E. (1986) Stimulation of raphe (obscurus) nucleus causes long-term potentiation of phrenic nerve activity in cat. J. Physiol. 381: $169-179$.

Millhorn, D. E., F. L. Eldridge, and T. G. Waldrop (1980) Prolonged stimulation of respiration by endogenous central serotonin. Resp. Physiol. 42: 171-188.

Millhorn, D. E., T. Hökfelt, K. Seroogy, W. Oertel, A. A. J. Verhofstad, and J.-Y. Wu (1987) Immunohistochemical evidence for colocalization of gamma-aminobutyric acid and serotonin in neurons of the

\footnotetext{
Figure 6. Electron micrographs of 2 serotonin synapses on a distal dendrite of an electrophysiologically identified phrenic motoneuron. The central micrograph at low magnification shows a portion of a dendrite $(D D)$ that was located more than $500 \mu \mathrm{m}$ from the cell body of an HRP-filled phrenic motoneuron. Two palely immunoreactive, serotonin-containing boutons that form synapses on the dendrite are indicated by the boxes marked $A$ and $B$ in this micrograph. $A I-A 3$ and $B I-B 3$, Micrographs of some of the serial sections through the 2 serotonin-positive boutons. Synaptic specializations are indicated by arrowheads and shown at higher magnification in $\mathrm{A} 1^{\prime}-\mathrm{A} 3^{\prime}$ and $\mathrm{B} 2{ }^{\prime}$. The numbers in the open arrows indicate the number of ultrathin sections separating the sections from which the micrographs were taken. The synapse in $A$ was extensive, being apparent in 12 serial sections. The synapse in $A$ was doughnut-shaped: the single postsynaptic density $(A I)$ became $2(A 2)$ and then merged into one $(A 3)$ when followed through serial sections. The synapse in $B$ was small; it was present in only 4 serial sections. The asterisks indicate nonimmunoreactive boutons. Scale bar in the low power micrograph, $2 \mu \mathrm{m}$; all other scale bars, $500 \mathrm{~nm}$. Scale bar in $A 1$ applies to $A 1-A 3$, in $B I$ to $B I-B 3$, and in $A I^{\prime}$ to $A I^{\prime}-A 3^{\prime}$.
} 
ventral medulla oblongata projecting to the spinal cord. Brain Res. 410: 179-185.

Mulligan, K. A., and I. Tork (1988) Serotoninergic innervation of the cat cerebral cortex. J. Comp. Ncurol. 270: 86-110.

Oldfield, B. J., A. Hou-Yu, and A.-J. Silverman (1983) Technique for the simultaneous ultrastructural demonstration of anterogradely transported horseradish peroxidase and an immunocytochemically identified neuropeptide. J. Histochem. Cytochem. 31: 1145-1150.

Pelletier, G., H. W. M. Steinbusch, and A. A. J. Verhofstad (1981) Immunoreactive substance $P$ and serotonin present in the same densecore vesicles. Nature 293: 71-72.

Pilowsky, P. M., J. B. Minson, A. J. Hodgson, P. R. C. Howe, and J. P. Chalmers (1986) Does substance P coexist with adrenaline in neurons of the rostral ventrolateral medulla in the rat. Neurosci. Lett. 71: 293-298.

Straus, W. (1982) Imidazole increases the sensitivity of the cytochemical reaction for peroxidase with diaminobenzidine at a neutral $\mathrm{pH}$. J. Histochem. Cytochem. 30: 491-492.

Takahashi, K., and T. Ninomiya (1985) Observations on the fine structure of the phrenic nucleus in the cervical spinal cord of the cat with special reference to its dendritic bundles. J. Anat. 140: 491-498.

Tashiro, T., and M. A. Ruda (1988) Immunocytochemical identification of axons containing coexistent serotonin and substance $P$ in the cat lumbar spinal cord. Peptides 9: 383-391.

Ulfhake, B., S. Cullheim, T. Hökfelt, and T. J. Visser (1987) The combined use of immunohistochemistry and intracellular staining with horseradish peroxidase for light and electron microscopic studies of transmitter identified inputs to functionally characterized neurons. Brain Res. 419: 387-391.

Van Dongen, P. A., S. Grillner, and T. Hökfelt (1986) 5-Hydroxytryptaminc (serotonin) causes a reduction in the after hyperpolarization following the action potential in lamprey motoneurons and premotor interneurons. Brain Res. 366: 320-325.

Voss, M. D., D. de Castro, J. Lipski, P. M. Pilowsky, and C. Jiang (1990) Serotonin immunoreactive boutons form close appositions with respiratory neurons of the dorsal respiratory group in the cat. J. Comp. Neurol. (in press).

Wessendorf, M. W., and R. Elde (1988) The coexistence of serotoninand substance P-like immunoreactivity in the spinal cord of the rat as shown by immunofluorescent double labeling. J. Neurosci. 7:23522363.

Wessendorf, M. W., H. K. Proudfit, and E. G. Anderson (1981) The identification of serotonergic neurons in the nucleus raphe magnus by conduction velocity. Brain Res. 214: 168-173.

Whitc, S. R., and R. S. Ncuman (1980) Facilitation of spinal motoneurone excitability by 5 -hydroxytryptamine and noradrenaline. Brain Res. 188: 119-127.

Yen, C.-T., and P. S. Blum (1984) Response properties and functional organization of neurons in midline region of medullary reticular formation of cats. J. Neurophysiol. 52: 961-979.

Zhan, W.-Z., H. H. Ellenberger, and J. L. Feldman (1989) Monoaminergic and GABAergic terminations in phrenic nucleus of rat identified by immunohistochemical labelling. Neuroscience $31:$ 105-113. 